\title{
Direkt und effizient
}

_ Neulich war ich froh, dass ich mir den Gang zum Hausarzt sparen konnte. Zu ihm kann ich wochentags zwar jederzeit ohne Termin gehen, in der Praxis muss ich aber fast immer ein Stunde und mehr warten, bis ich überhaupt zu ihm ins Besprechungszimmer gerufen werde. Der hätte mir dann vermutlich auf meine Bitte hin eine Verordnung für Physiotherapie ausgestellt oder mich an den Orthopäden überwiesen. Was nicht in meinem Sinne gewesen wäre. Sind doch die Orthopäden in Heidelberg sehr gefragt und Termine meist nicht zeitnah zu bekommen. Und ich wollte schnelle Hilfe.

_ Doch zum Glück kam alles anders. Ich erzählte meiner Kollegin, dass ich starke

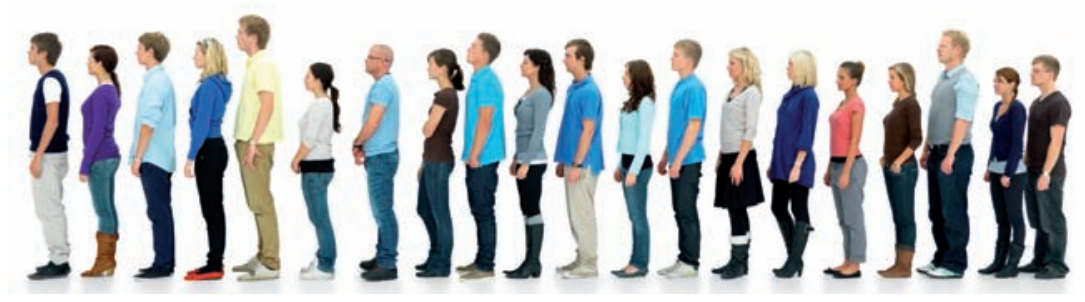
Schmerzen in der rechten Schulter habe, die in den Arm ziehen, der kraftlos ist. Eine Wasserflasche kann ich kaum tragen, und den Arm mag ich nicht bewegen. Meine Kollegin - ganz Physiotherapeutin fackelte nicht lange herum, schloss die Tür, bat mich, auf den Stuhl zu setzen, und machte spezifische Schultertests, bis sie erkennen konnte, welche Stellung die schmerzauslösende ist. Dann drückte sie auf einen Triggerpunkt - eine schmerzhafte Angelegenheit, doch definitiv wirksam - und wiederholte das Ganze an anderer Stelle. Anschließend zeigte sie mir zwei Übungen für zu Hause. Zusammen hat das nicht einmal zehn Minuten gedauert, war jedoch absolut effektiv und wirkungsvoll: Der Schmerz schwand deutlich, und die Kraft kehrte in den Arm zurück. Ich machte zu Hause und auf der Arbeit die Übungen, eine weitere Behandlung durch meine Kollegin war nicht mehr notwendig.

_Gäbe es in Deutschland den Direktzugang, wäre ich schnurstracks zum Physiotherapeuten gegangen, weil ich mir sicher war: Bei muskulären Problemen ist er der Experte. Und wie meine Erfahrung zeigte, lag ich richtig. Unterm Strich hat das zu einer schnellen Linderung meiner Beschwerden geführt, mir jede Menge Zeit gespart und die Krankenkasse einiges an Geld. Eine Behandlungseinheit hätte ja gereicht. Ein flexibles Verordnungssystem hätte also etwas für sich, genauso wie der Direktzugang. Ich bin gespannt, was 2012 bringen wird.

Herzlich, Ihre

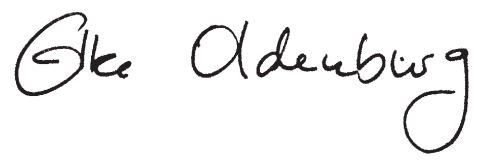

\section{ZU GEWIINNEN}

In jeder physiopraxis werden attraktive Gewinne verlost. Möchten Sie einen ergattern, klicken Sie unter www.thieme.de/physioonline auf „physio-exklusiv“.

Und das gibt es in dieser Ausgabe zu gewinnen:

Bücher

2-mal „Physiotherapie in der Gynäkologie“

Seite 36

2-mal „Mulligan“

Seite 42

2-mal „Früher war hier das Ende der Welt"

Seite 48

und außerdem

1 Backgammon-Spiel

Seite 32

1 Dartscheibe

Seite 32

1 Kopfmodell 